\title{
Blameworthiness and the Outcomes of One's Actions
}

\author{
Ambrose Y. K. Lee ${ }^{1}$ (D)
}

Accepted: 8 October 2021

(C) The Author(s) 2021

\begin{abstract}
There are at least two ways to argue for the view that the outcome of one's actions does not affect one's blameworthiness. The first way appeals to the 'Control Principle' while the second way relies on what it means to be blameworthy. The focus of this paper is on a recent attempt at pursuing this second way that relies on an account of blameworthiness dubbed the 'Engagement View'. This paper argues, however, that the Engagement View alone is insufficient to show why the outcomes of one's actions does not affect one's blameworthiness. It argues that if blame is understood more robustly as involving reactive attitudes like resentment and indignation, then it turns out the Engagement View can also give us reasons for the contrary view. This paper ends by drawing out some general implications that this has on our understanding of blameworthiness.
\end{abstract}

Keyword Blameworthiness $\cdot$ Punishment $\cdot$ Outcome luck $\cdot$ Reactive attitudes $\cdot$ The engagement view

\section{Two Ways to Argue for Outcomes Insensitivity}

Should the criminal law be sensitive to the outcomes of our actions? In particular, besides distinguishing between completed attempts that are successful from those that are unsuccessful, should the former be punished, for example, more severely than the latter?

Imagine two assassins, $\mathrm{A}$ and $\mathrm{B}$, who both made an attempt at their respective victim's life. Both of their attempts were otherwise identical in every way besides the following: while the bullet from A's gun hit and killed his victim as A planned, the bullet from B's gun did not because a bird unexpectedly flew into the path of the bullet and the bullet hit and killed the bird instead. Should these two assassins be

Ambrose Y. K. Lee

y.a.lee@ surrey.ac.uk

1 School of Law, Faculty of Arts and Social Sciences, University of Surrey,

Guildford, Surrey GU2 7XH, UK 
treated differently just because there is this difference in the outcomes of their otherwise identical actions? ${ }^{1}$

According to one view (call it the 'Outcomes-sensitive View'), they should be treated differently. This is because A's action did end up killing someone while B's action did not. For this reason, A therefore, according to this view, deserves more blame and merits more censure than B; and if their punishments are to accurately reflect the blame and censure that each of them deserves, then A should be punished more severely than B.

In response to this view, one might argue that the outcomes of one's action should not make a difference to the blame and censure that one deserves (call this the 'Outcomes-insensitive View'). There are two ways to argue for this view.

The first way appeals to what is referred to as the 'Control Principle'. This principle stipulates control as a condition for moral responsibility. More specifically, according to this principle, "[w]e are morally assessable only to the extent that what we are assessed for depends on factors under our control". This in turn implies that "[t]wo people ought not to be morally assessed differently if the differences between them are due only to factors beyond their control'. ${ }^{2}$

As the above imaginary example demonstrates, whether A's or B's attempt does end up killing their intended victim depends on 'factors beyond their control'. ${ }^{3} \mathrm{Had}$ the bird not unexpectedly flew into the path of B's bullet, then B's attempt would have been successful. Had it unexpectedly flew into the path of A's bullet instead, then A's attempt would have been unsuccessful. Accordingly, whether A or B actually killed someone is therefore-if one accepts the Control Principle-irrelevant to assessing what they each have done. Furthermore, given that their attempts were otherwise identical in every other way, they should therefore be assessed in exactly the same way. A and B should therefore be held responsible and be labelled in the same way, as 'attempted murderers' for example and be punished to the same extent. That is assuming, of course, that they are indeed morally responsible for their attempts.

The problem with appealing to the Control Principle is that it is very hard to simply contain it to the case at hand. This is because whether one makes the attempt in question also depends on factors that are beyond one's control. It depends on one's 'constitution' so to speak, on how resilient, for example, one is to the temptations

\footnotetext{
1 This example is drawn from James Edwards and Andrew Simester, 'Crime, Blameworthiness, and Outcomes' (2019) 39 OJLS 50, 52.

2 Dana K Nelkin, 'Moral Luck' in Edward N Zalta (ed), The Stanford Encyclopedia of Philosophy (Summer 2019 Edition)<https://plato.stanford.edu/archives/sum2019/entries/moral-luck/>accessed 13 August 2020. See also David Enoch and Andrei Marmor, 'The Case Against Moral Luck' (2007) 26 Law and Philosophy 405, 405; and Michael Zimmerman, 'Taking Luck Seriously' (2002) 99 Journal of Philosophy 553, 556-560. Note that we are talking about 'hypological' judgements here, and not 'deontic' or 'aretaic' judgements (ibid 554).

3 There are at least two ways to understand the notion of 'control' here in the Control Principle. The first way requires that we have complete control over the factors in question, while the second way only requires that we have (in some specified sense) sufficient control over them. This paper only focuses on the first more demanding way of understanding the Control Principle. For a discussion of these two ways of understanding 'control', see Michael Moore, Placing Blame (OUP 1997) 211-218.
} 
to commit a crime. This in turn depends on how one is brought up, the experiences that one has and the environment in which one grows up. Whether one makes an attempt also depends on the circumstances in which one finds oneself. It depends on, for example, whether one is afforded the opportunity to do so. Thus in the above imaginary example, it is very likely that, all things being equal, had A and B not been hired to kill their respective victims-because no one recognised their skills as assassins-then they would not have made the attempts on their victims' lives. The issue here is that we often lack control over these factors, on how we so happen to be constituted and the circumstances in which we find ourselves. Given that our attempts depend on such factors that are often beyond our control, the Control Principle therefore implies we should not only not be assessed for the outcomes of our attempts, but also not be assessed for our attempts as well. Generalising from this, if we take the Control Principle to its logical extreme, it seems to imply, in Nagel's alltoo-frequently quoted words, that "[t]he area of... legitimate moral judgment, seems to shrink under this scrutiny to an extensionless point". 4

Some take this to be a reductio against the Control Principle. ${ }^{5}$ Others embrace it as an argument for the conclusion that no one really deserves to be blamed and/ or punished insofar as these involve an adverse assessment of someone for what she has done. After all, one person's modus tollens is another's modus ponens. We therefore should, according to them, revise our practices of blaming and punishment in light of this conclusion. ${ }^{6}$ Still others resist both the reductio and its 'absurd' conclusion, either by arguing that there can still be a kind of moral assessment that can properly ground blame (and punishment) but which does not fall foul of the Control Principle, ${ }^{7}$ or by finding various ways to limit the reach of the Control Principle. ${ }^{8}$

I only mention the Control Principle in order to set it aside for the purposes of this paper. I do think the Control Principle does pose a genuine challenge to those who think that the outcomes of one's actions should make a difference to the amount of blame (and punishment) that one deserves. I shall say a bit more about this at the end of the paper. However, what I want to focus on in this paper is the second way of responding to the Outcomes-sensitive View and in favour of an Outcomesinsensitive View.

\footnotetext{
4 Thomas Nagel, 'Moral Luck' in Mortal Questions (CUP 1979) 35.

5 Edwards and Simester (n 1) 53-54. See also Moore (n 3) 233-246.

6 See e.g. Neil Levy, Hard Luck (OUP 2011); Derek Pereboom, 'Free Will Skepticism, Blame, and Obligation' in D Justin Coates and Neal A Tognazzini (eds), Blame: Its Nature and Norms (OUP 2012) 189-206, and 'Free Will Skepticism and Criminal Punishment' in Thomas Nadelhoffer (ed), The Future of Punishment (OUP 2013) 49-78.

7 See e.g. Zimmerman (n 2) 563-576.

${ }^{8}$ For a critical discussion of whether this is a stable position, see Robert J Hartman, 'Moral Luck and the Unfairness of Morality' (2019) 176 Philosophical Studies 3179.
} 


\section{Focusing on the Second Way}

This second way relies not on the Control Principle, but on what it means to be blameworthy. One recent attempt at pursuing this was made by Edwards and Simester. ${ }^{9}$ According to them, to find someone blameworthy-that is worthy of blame-is not simply to make a moral assessment of the agent's actions (i.e. that they were wrong) or of the agent simpliciter. ${ }^{10}$ Rather it is to make a moral assessment of the agent in respect of her actions. It is to judge that what she has done reflects badly on her and that it is appropriate to view her in a worse light in virtue of the wrong that she has committed. ${ }^{11}$

When is it appropriate to view an agent in a worse light in virtue of her wrong? Edwards and Simester's answer to this is what they refer to as 'the Engagement View'. According to this view, what makes someone blameworthy for committing a wrong is a matter of her engagement with the reasons that bear on what she has done. In particular, it is about the extent to which she failed to engage in her practical reasoning the reasons that make what she has done a wrong (Edwards and Simester call these "guiding reasons"). As they put it succinctly, "D is blameworthy for Øing in virtue of the fact that D's engagement with those reasons exhibits some shortfall or deficiency, relative to what we can reasonably expect from D". ${ }^{12}$

A simple example will serve to illustrate the Engagement View. One plausible guiding reason against me punching you in the face is that it will hurt you. I am therefore blameworthy for hitting you if in the course of my practical reasoning that led to my punching of you in the face, I failed to properly engage with that (or other) guiding reasons against punching you in a way that can reasonably be expected of me. I can fail to do this in a variety of ways. I can, for example, punch you in order to hurt you because I was angry with you and really wanted to hurt you; or I may take it as more important to show off to my friends my manliness by punching you than to respect your interest in not getting hurt. In both cases, my failure to properly engage with the guiding reasons against hitting you reflects badly on me, and to that extent I am blameworthy for hitting you according to the Engagement View. Of course, not all cases of me punching you in the face will reflect badly on me. I might have been acting on what is indeed an adequate justification for hitting you. In that case I have not failed to properly engage with the guiding reasons against hitting you. Or I might be hitting you out of self-defence because I mistakenly but reasonably thought that you were attacking me. In such a case, while I might have failed to properly engage with the guiding reasons in question, I arguably have not fallen short of what can reasonably be expected of me. It is only when one's engagement in one's practical reasoning falls short of what can reasonably be expected of one, that what one does as a result of one's practical reasoning reflects badly on one and therefore makes one blameworthy for doing it.

\footnotetext{
${ }^{9}$ Edwards and Simester (n 1).

${ }^{10}$ Recall the distinctions between hypological, deontic and aretaic judgements in $\mathrm{n} 2$.

11 Edwards and Simester (n 1) 6-7.

12 ibid 7.
} 
Following Edwards and Simester, I have so far only focused on intentional wrongs in my explanation of the Engagement View. However, it is easy to see how one is also failing to properly engage with the guiding reasons that bear on one's action, in a way that reflects badly on one, when one is reckless to the harm that one's action might cause to others or is negligent about it (I shall come back to negligence in the next paragraph). However, for ease of exposition, I shall mainly be focusing on the paradigmatic case of intentional wrongs in this paper.

It is important to note that failing to engage in the way described by the Engagement View is not by itself sufficient for blameworthiness. As Edwards and Simester argue, we need to maintain a distinction between the grounds for blameworthiness-which is the failure to engage as described by the Engagement View-and the preconditions for blameworthiness. Examples of the latter include the requirements of voluntariness and sanity in the criminal law, ${ }^{13}$ and that the actor is a moral agent, which is fleshed out by Edwards and Simester as "... someone whose actions are responsive to a set of values with which she identifies". ${ }^{14}$ There is no reason to think, neither is it claimed by Edwards and Simester, that these examples exhaust the preconditions for blameworthiness. Thus, even if one fails to properly engage with guiding reasons when one is negligent, one might still not be blameworthy on account of negligence not satisfying all the preconditions for blameworthiness. This would be the case if, for example, one precondition for blameworthiness is that one is at least aware of the fact that one's action risks harm on others. ${ }^{15}$ In any case, whether negligence can ground blameworthiness is something that Edwards and Simester want to leave open for the Engagement View. ${ }^{16}$ They are only keen to reject the Control Principle as a precondition for blameworthiness. ${ }^{17}$

Relating all this back to the imaginary example of the two assassins. According to the Engagement View, both A and B are equally blameworthy. This is because both of them failed to properly engage with the guiding reasons against shooting their victims in the same way. After all, ex hypothesi their attempts were identical in every way besides the outcomes of their respective actions. If A and B are equally blameworthy, then they should be subjected to the same level of blame; and if their punishments are to accurately reflect the level of blame that A and B are worthy of, then they should be punished as severely as each other. Hence we should accept the Outcomes-insensitive View as opposed to the Outcomes-sensitive View.

The Outcomes-insensitive View does not necessarily exclude punishing A or B more severely than the other. As Edwards and Simester point out, the claim that punishments should track blameworthiness is most plausibly only a ceteris paribus claim. ${ }^{18}$ While accurately reflecting, expressing and/or communicating the blame that the punished are worthy of is a plausible justifying aim of punishment, it is

\footnotetext{
13 ibid fn 21.

14 ibid 12-13.

15 See e.g. Larry Alexander and Kimberly K Ferzan, Crime and Culpability (CUP 2009) ch 3.

16 Edwards and Simester (n 1) 7 fn 7.

17 ibid 12-13.

18 ibid 2.
} 
also arguably not the only justifying aim of punishment. Depending on what these other aims are, they might therefore end up calling for differential punishments of $\mathrm{A}$ and $\mathrm{B}$ in light of the outcomes of their actions even under the Outcomes-insensitive View. Thus, for example, there might be reasons to incapacitate B and not A because B will most likely make another attempt at her victim's life in light of her failure, while A will not as she was successful in her attempt (and assuming that she will not try to kill others in the future). Conversely, if one justifying aim of punishment is that it helps to displace victims from seeking revenge against those who have wrongfully harmed them, ${ }^{19}$ then there can also be reasons to punish A more severely than B because of the outcomes of their actions. There might also be noninstrumental considerations for punishing A and B differently. Yaffe, for example, argues that while cases like A and B are equally blameworthy and therefore should both be subjected to the same degree of censure, there can nevertheless be reasons to impose more sanctions on A to "acknowledge the injury [that A has done] to the victim". ${ }^{20}$ Furthermore, as Edwards and Simester argue, even though A and B are equally blameworthy and should therefore-all else being equal-be punished as severely as each other, they should nevertheless be convicted of different crimes due to considerations of fair labelling. ${ }^{21}$

What I therefore take to be central to the Outcomes-insensitive View, at least for the purposes of this paper, is not that the outcomes of one's (wrongful) actions should never make a difference to punishments and/or the crimes that one is convicted of. Rather, it is that they do not make a difference to how blameworthy one is-that is, how much blame one is worthy of-and that this therefore constitutes at least a defeasible reason for punishments and/or definitions of crimes to be insensitive to outcomes. It is this central claim that I am referring to when I talk about the 'Outcomes-insensitive View' in this paper.

\section{An Outline of My Argument and Further Clarifications}

To be clear, my aim is not to argue against the Outcomes-insensitive View and defend the Outcomes-sensitive View more generally. As I explained earlier, I do think that the Control Principle does pose a genuine challenge to the Outcomessensitive View. Nothing that I shall argue for in this paper will help the Outcomessensitive View to address that challenge. Rather, the aim of this paper is simply to show that the second way of arguing for the Outcomes-insensitive View, by relying on the nature of blameworthiness and the Engagement View in particular, is not a strong one. This is because, as I shall argue in the remainder of this paper, they do

\footnotetext{
19 John Gardner, 'Crime: In Proportion and in Perspective' in Offences and Defences (OUP 2007) 213238.

20 Gideon Yaffe, Attempts (2010 OUP) 324-327.

${ }^{21}$ Edwards and Simester (n 1) 14-16. Hence they distinguish between punishment being sensitive to outcomes and definitions of crimes being sensitive to outcomes, arguing for the latter and against the former.
} 
not show, or at least do not necessarily imply, that the outcomes of one's wrongful actions should not make a difference to how blameworthy one is.

To that end, I shall therefore be accepting the Engagement View for the purposes of this paper. The aim is not to reject it but to ask whether it gives us good reasons for accepting the Outcomes-insensitive View. In any case, I do think that the Engagement View is a plausible account of fault and what makes those who are at fault blameworthy. ${ }^{22}$ I agree with the Engagement View that failing to properly engage with guiding reasons as one should in one's practical reasoning makes one blameworthy. It makes one worthy of blame. However, there are two issues here. The first issue is whether one is worthy of blame and what it is that makes one worthy of blame. The focus here is on the agent herself and whether her actions (and their outcomes) are connected to her in a way that makes her worthy of blame in relation to them. The second issue is how much blame one is worthy of. This is a function of what exactly one has done that is worthy of blame and how much blame it is worthy of (or merits or warrants-I take these terms to be synonymous for the purposes of this paper, though I shall mainly speak in terms of 'merit' in the following to better distinguish this second issue from the first issue). All things being equal, the more serious one's moral failings are, the more severe the blame that is merited by the failing and therefore the more blame one is worthy of, and vice versa.

The Engagement View addresses both issues at once. It gives us a story about when one is worthy of blame and what it is that makes one worthy of blame. It also addresses the second issue about how much blame one is worthy of, at least in relation to that which makes one worthy of blame. All things being equal, the more serious is one's failure to properly engage with guiding reasons as one should in one's practical reasoning, the more severe is the blame that is merited by the failure and therefore the more blame one is worthy of in relation to that failure.

One question to ask here is whether the Engagement View can accurately capture how much blame one is worthy of in relation to one's actions considered independently from their outcomes (i.e. one's 'tryings' and 'riskings' so to speak). That is not the concern of this paper. ${ }^{23}$ However, even if we assume that the Engagement View is accurate on that front, failing to properly engage with reasons in one's practical reasoning is only one aspect of what one has done when one commits a culpable wrong. ${ }^{24}$ If one's wrongful action also successfully brings about the wrongful

\footnotetext{
${ }^{22}$ I do think, as I have suggested earlier, that more needs to be said about the preconditions for blameworthiness; but I would like to put this to one side for the purposes of this paper.

23 One might draw a distinction between the actual level of one's failure to engage and the level that is manifested in one's behaviour and actions, and argue that the level of blame one is worthy of should track the latter rather than the former. For a discussion of this in relation to another account that is very similar to the Engagement View, see Alexander Sarch, 'Who Cares What You Think? Criminal Culpability and the Irrelevance of Unmanifested Mental States' (2017) 36 Law and Philosophy 707.

24 Following Edwards and Simester, my focus here is on one's blameworthiness for one's wrongful action and not simply for one's practical reasoning. I leave it open as to whether one can be blameworthy simply for one's practical reasoning prior to or independent from its manifestation in one's wrongful behaviour, and whether this is implied by the Engagement View. For a defence of the view that actions are not necessary for being blameworthy, see Peter A Graham, 'A Sketch of a Theory of Moral Blameworthiness' (2014) 88 Philosophy and Phenomenological Research 388, 396-399.
} 
outcome, then this outcome is also part of what one has done; and if that outcome also independently merits blame, then more blame is merited than if the wrongful outcome was not brought about. The outcome of one's action can therefore, in this way, make one worthy of more blame. ${ }^{25}$

Of course, if one thinks that the outcome of one's wrongful action is not part of what one has done, then it cannot make one worthy of more blame in this way. But this is not the view held by Edwards and Simester. Recall that they reject the Control Principle. ${ }^{26}$ They therefore do not think that one cannot be morally responsible for and be held responsible for the outcomes of one's wrongful actions because they are not, for example, within one's control. In fact, they argue for the opposite view. They argue that those whose wrongful action brings about the wrongful outcome commit a different wrong or an additional wrong than those whose wrongful action did not bring about the outcome in question. ${ }^{27}$ They also argue that the former owe secondary duties of compensation in virtue of bringing about the wrongful outcome and that it is appropriate for them to regret the outcome brought about by their wrongful actions. ${ }^{28}$ If we accept that the outcome of one's wrongful action is part of what one has done, that one is morally responsible for it and can be held morally responsible for it, then the question is whether the outcome of one's wrongful action can also independently merit blame. If it can, then it can also make one worthy of more blame, or so I have argued above.

The rest of this paper is devoted to defending the claim that the outcome of one's wrongful action can indeed independently merit blame. My argument will rely on the Engagement View. In particular, we need to ask why failing to properly engage with reasons in the way described by the Engagement View makes one worthy of blame for what one has done-just what exactly is it about such a failure that merits it? My argument is that the reason that shows why such a failure merits blame also shows why the outcome of one's actions can also independently merit blame.

Of course, the answer to the above question will depend on what exactly it is that we are doing when we blame others. I shall argue that we should ask the above question not simply in relation to a thin understanding of blame, as an entry in one's 'moral ledger' for example, ${ }^{29}$ but also in relation to a more robust understanding of blame. One that involves certain 'reactive attitudes'.

\footnotetext{
${ }^{25}$ Following on from the previous footnote, a similar question can also be asked about whether one's wrongful action, assuming that it can be considered independently from one's practical reasoning, can also independently merit blame. I do not know the answer to this; but given this is not the dispute between the Outcomes-insensitive View and the Outcomes-sensitive View, and it does not bear on the Engagement View's defence of the former, I shall simply leave this question aside for the purposes of this paper.

26 Edwards and Simester (n 1) 53-54.

27 ibid 57 (for 'different wrong') and 65 (for 'additional wrong').

28 ibid 58 and 67.

29 Zimmerman (n 2) 555-556.

30 Prominent defenders of such accounts of blame include Peter F Strawson, 'Freedom and Resentment' in Gary Watson (ed), Free Will ( $2^{\text {nd }}$ edn, OUP 2003) 72-93; and Jay Wallace, 'Dispassionate Opprobrium: On Blame and the Reactive Sentiments' in Wallace et al. (eds), Reasons and Recognition: Essays on the Philosophy of T. M. Scanlon (OUP 2011) 348-372.
} 
There are other arguments for the Outcomes-sensitive View that also appeal to reactive attitudes. ${ }^{31}$ However, my argument is slightly different. It does not simply rely on how our reactive attitudes differ depending on the outcomes of one's action, and how it is appropriate for us to react differently in light of the outcomes of one's action. Rather, my argument relies on asking what it is that merits blame, merits being subjected to such reactive attitudes, when one fails to properly engage with reasons in the way described by the Engagement View. It then argues that, for the same reason, the outcome of one's action can also merit blame and can therefore also affect how much blame one is worthy of. Rather than relying on how it is appropriate for us to react differently in light of the outcomes of one's action, my argument therefore instead seeks to show that it can be appropriate by relying on the Engagement View and to argue how it can give us reasons for thinking that is true. I am aware that this does not make my argument immune from all the sceptical arguments against reactive attitudes. I shall address some of them in the course of developing my argument.

\section{Getting Clear on the Question}

With that in mind, let me move on to the question that I propose to ask-why does failing to properly engage with reasons in the way described in the Engagement View make one worthy of blame for what one has done? Just what exactly is it about such a failure that merits it?

Not surprisingly, a lot depends on what it means to 'blame' someone for what she has done. According to what can be referred to as the 'ledger view' of blame, to blame someone "is simply to make [an adverse] judgement about her moral record". It is, as it were, to put a negative "entry" in one's "moral ledger", a strike against one's "moral record as a person" so to speak. ${ }^{32}$ Of course, not all failures to engage with reasons properly can count as moral failures and be 'entered' into one's moral record. However, if we limit the failures in question to that of engagement with moral reasons, then it is easy to see why such failures merit a negative 'entry' in one's moral record. ${ }^{33}$

The ledger view of blame dovetails very nicely with the Engagement View. Given that the kind of failures described in the Engagement View reflect badly on one, it therefore seems quite plausible that they can merit a negative entry on one's moral record. Hence, as long as such failures are limited to that of engagement with moral reasons, they are, as the Engagement View rightly holds, grounds for blameworthiness. They make one worthy of blame. On the other hand, the outcomes of one's actions, as the assassins example shows, do not reflect badly on one. The fact that

\footnotetext{
31 See e.g. Michael Moore, Causation and Responsibility (OUP 2009) 29-31.

32 Zimmerman (n 2) 555-556.

33 One of the strengths of the Engagement View is that it can account for non-moral blame (if there can be such a thing), if we understand the failure to be of engagement with non-moral reasons as opposed to moral reasons.
} 
A succeeded in his attempt that is otherwise equal to that of B does not show $\mathrm{A}$ in a worse light, neither does B's failure show B in a better light. It seems plausible to think that only moral failures that reflect badly on one can merit a negative entry on one's moral record. Thus, as argued by the Engagement View, the outcomes of one's action cannot be plausible grounds for blameworthiness. Although Edwards and Simester do not explicitly refer to the ledger view when discussing their Engagement View, it seems reasonable to assume this might be what they had in mind given their references when explaining the Engagement View. ${ }^{34}$

Nevertheless, the problem with the ledger view is not so much that it is incorrect, but that it is incomplete. To blame someone no doubt is to make an adverse judgement about her moral record, to put an 'entry' in her 'moral ledger' so to speak; but blame involves more than simply record keeping. It also typically and paradigmatically involves modifying one's behaviour and interactions (especially in relation to those who one blames) in light of these adverse judgements. ${ }^{35}$ But more importantly for the purposes of this paper, it also involves having certain emotional reactions towards those who one is blaming; or in the terminology used in the literature, it involves having certain 'reactive attitudes', e.g. resentment or indignation, towards those who one judges to be blameworthy.

Thus one problem with the ledger view is that it seems to render blame 'bloodless'-a familiar charge that is often launched also against Scanlon's account of blame. ${ }^{36}$ As Zimmerman, an advocate of the ledger view, puts it, to "blame someone, in this sense, is simply to make a judgement about her moral record. A judgement which may form the basis of, but which is not itself, a 'reaction' either in attitude or in some more robust form of behavior toward that person". 37

It is not the aim of this paper to defend any particular account of what it means to 'blame' someone for what they have done. My point is just that blame frequently and typically involves not just making and recording an adverse judgement about someone's moral record but also having (and expressing in cases of overt blame) certain reactive attitudes towards those who one judges as worthy of blame. When asking what exactly it is that makes one worthy of blame for what one has done, we therefore should not simply limit ourselves to asking what exactly it is that makes one worthy of blame in this thin sense of making and recording an adverse judgement about one's moral record. We should also ask what exactly it is that makes one worthy of blame in this more robust sense of being subjected to such reactive attitudes. Accordingly, the question that I propose to ask in relation to the Engagement View in the beginning of this section should therefore be asked and addressed with this more robust sense of 'blame' in mind: why does failing to properly engage with reasons in the way described by the Engagement View make one worthy of blame in the sense of being subjected to such reactive attitudes? Just what exactly is it about

\footnotetext{
${ }^{34}$ See e.g. Edwards and Simester (n 1) fns 18 and 43.

35 T M Scanlon, Moral Dimensions (Harvard University Press 2008) 128-129.

36 Wallace (n 30) 349.

37 Zimmerman (n 2) 556. My italics.
} 
such a failure that merits not just an adverse judgement about one's moral record but also, for example, resentment?

One might worry at this point that I am conflating the distinction between blameworthiness and what can be referred to as 'blame-related reactions'. The latter include, but are not limited to, the kinds of reactive attitudes that I have talked about in the above. ${ }^{38}$ Now, I do want to deny that at least when it comes to certain kinds of reactive attitudes, most paradigmatically resentment and indignation, they are not simply 'blame-related reactions'. Rather, we should see them, as I try to argue in the above, as part of the blaming response and therefore as part of what one is worthy of when one is worthy of blame. Nevertheless, this does not imply that there is no distinction between blameworthiness-that is, one's worthiness to being subjected to such reactive attitudes- and the reactive attitudes themselves; nor does it imply the view that blameworthiness simply consists in the appropriateness of such reactive attitudes. ${ }^{39}$ Rather, the claim is just that being blameworthy, i.e. worthy of blame, is at least partly being worthy of being subjected to such reactive attitudes. Thus we should ask, not just why those who are blameworthy according to the Engagement View are, for example, worthy of having adverse judgements made about their moral records, but also why they are worthy of being subjected to such reactive attitudes.

\section{Why does Failing to Engage Merit Blame?}

Here is one possible answer to the question. Failing to properly engage with reasons in the way described by the Engagement View reflects badly on one and shows one in a worse light. One might therefore argue that it is precisely because it reflects badly on one and shows one in a worse light that those who so fail when they act are worthy of and merit resentment for what they have done.

This, however, cannot be the right answer. It cannot be the right answer because showing oneself in a worse light per se does not make one worthy of resentment for what one has done any more than it makes one worthy of disappointment or sadness. It is the kind of failure that reflects badly on one that determines what one is worthy of and not simply the fact that one is shown in a worse light. Accordingly, the reason why those who fail to properly engage with reasons when they act merit resentment for what they have done cannot simply be that their failure to do so reflects badly on them and shows them in a worse light. Rather, it is the nature of the failure itself that is the reason.

I therefore think that the more plausible answer to the question (and the one that is more intuitive) is simply that in failing to properly engage with reasons in the way described by the Engagement View, one has failed to conform to a moral requirement that one owes us, and to which we can legitimately and reasonably expect and demand her conformance. This, I argue, is the more plausible reason for why those who fail in such a way when they act are worthy of and merit resentment for

\footnotetext{
38 Enoch and Marmor (n 2) 412-413.

39 See ibid 432-434 for a critical discussion of such a view.
} 
what they have done. We all, for example, have a strong reason not to hurt others. What this requires of us, of course, is that we actually not hurt others through our actions, at least not unjustifiably. But, putting this to one side for now (I shall return to it in the next section), what is more important for our purposes here is that it also requires us to properly engage with this reason against hurting others in our practical reasoning when deciding what to do. We should, for example, consider whether what we want to do would risk hurting others. If so, we should decide against doing it if the risk is an unreasonable one; and we certainly should not decide to do something that is aimed at hurting others unless we have extremely good and weighty reasons to do so.

Of course, as the Engagement View makes clear, ${ }^{40}$ we are not required to properly engage with this (or any other reason) come what may and beyond what can reasonably be expected of us. We are only required to do so as it can reasonably be expected of us. ${ }^{41}$ Nevertheless, we are not simply advised to do what can reasonably be expected of us here. They are not optional. Rather, we are required to properly engage with this reason against hurting others as it can be reasonably expected of us in our practical reasoning. Failing to do so is not simply a failure in doing what we have some reasons to do, but a failure in doing what we are reasonably required to do.

Furthermore, this is not simply an impartial moral requirement. We owe it to others to properly engage with this reason against hurting others as reasonably required in our practical reasoning. We, as others who might be hurt by your actions, therefore have a standing expectation and demand that you conform to this requirement. Failing to properly engage with this reason against hurting us as it is reasonably required of you is therefore also a failure to respect our standing and authority as a source of legitimate claims and demands against you and your actions. This is best illustrated in the case at hand, where the reason against hurting others is plausibly grounded in their interest to not get hurt. In failing to properly engage with this reason in my practical deliberations as reasonably required, I am therefore failing to properly respect your interest in not getting hurt (assuming that you are one of those who might be hurt by my actions), and the legitimate claims and demands that your interest gives rise to. Not only is it natural for you to be angry and to resent me when I do this, it is also, I contend, reasonable for you to do so. This is especially the case when, as it is with the requirement to not hurt others, what is being required is not just a basic moral regard but is also mutual and reciprocal in nature. Not only do I owe it to you to engage with this reason in my practical deliberations, it is also something that you owe to me. After all, as I said in the beginning, we all have a strong reason not to hurt others. There are therefore more reasons for you to be

\footnotetext{
40 See text at $\mathrm{n} 12$.

41 Hence one is excused from committing a wrong in certain circumstances (e.g. under duress) because one cannot reasonably be expected in those circumstances to properly engage with the reason against committing the wrong in question. I tend to think that morality cannot require us beyond that which can reasonably be expected of us. If I am wrong here, then my contention would be that it would be unreasonable to demand and blame others for failing to do that which is beyond what can reasonably be expected of them.
} 
emotionally exercised when I fail to properly engage with this reason as required, for I have failed to give what is reasonably owed to you as you were required to give to me - that is, unless you are a hypocrite.

My discussion has so far focused on moral requirements of a particular kind - those that are owed to one and/or to others. I think these are paradigmatic cases for meriting resentment and indignation when one fails to conform to them. But not all moral requirements are owed to others. Some might just be impartially required. Maybe some requirements of justice are like that, required by justice but are not owed to anyone. I think failing to properly engage with these requirements as one can reasonably be expected to can also merit indignation by others, ${ }^{42}$ for there are good reasons to take seriously the requirements of justice and to care about whether people are conforming to them as reasonably required.

It is important to note that none of this implies that it is always or all-thingsconsidered justifiable to resent someone for what they have done whenever someone fails to properly engage with reasons in the way I have discussed when they act. By 'merit' and 'being worthy of', I simply mean that there is a reason to resent someone in virtue of their failure to properly engage with reasons when they act or that is at least pro tanto appropriate to do so in virtue of that. ${ }^{43}$ Whether it is all-thingsconsidered justifiable or appropriate to do so (not just in private but also to resent overtly) in any particular case, however, will depend on a whole host of additional considerations - e.g. whether the blamer has the standing to do so and whether there are any other considerations against it. A full account of when it is appropriate and justifiable to blame someone with resentment or indignation (call this 'resentful blame') will have to spell out all the additional conditions. However, this is not what I am trying to do here nor is it something I need to do for my purposes.

Given that the aim of this paper is not to defend a practice of resentful blame, but to ask what it is that merits and makes one worthy of blame for what one has done, I shall therefore not offer a full argument and defence for why failing to conform to what one is morally required does indeed merit resentment in the sense of it being a reason to resent the person in question. My view is that a full argument for this will involve more than what I have argued in the above. It will need to also explain how such reactive attitudes are means of registering and appreciating moral transgressions, ${ }^{44}$ and include a broader story about why it is important for us that we have such reactive attitudes and the role that they play in our moral lives. ${ }^{45}$ A full defence of resentful blame will also need to respond to those who argue that such reactive attitudes are never apt or appropriate responses to moral failings. ${ }^{46}$ While I think

\footnotetext{
$\overline{42}$ Admittedly this goes slightly beyond Strawson's view, since he limits the 'impersonal' character of indignation as responding to wrongs that are still at least directed at others. See Strawson (n 30) 83-84.

${ }^{43}$ Provided, of course, that the preconditions for blameworthiness are satisfied. See discussion at $\mathrm{n} 13$.

${ }^{44}$ Amia Srinivasan, 'The Aptness of Anger' (2018) 26 The Journal of Political Philosophy 123, 132133.

45 Jay Wallace, 'Trust, Anger, Resentment, Forgiveness: On Blame and its Reason' (2019) 27 European Journal of Philosophy 537, 541-544.

${ }^{46}$ A good summary of these arguments against resentful blame can be found in David Shoemaker, 'You Oughta Know: Defending Angry Blame' in M Cherry and O Flanagan (eds), Moral Psychology of the
} 
resentment and indignation is a kind of anger (more specifically, I follow D'Arms and Jacobson in seeing resentment as a kind of anger that is 'cognitively sharpened' with the belief that one has been wronged, ${ }^{47}$ and is directed at the person who one believes has committed the wrong in question in virtue of this belief), I do not think that the idea of payback or retribution is a conceptual part of anger and of resentment. ${ }^{48}$ Rather, what is more essential to resentment (and indignation) qua anger, in my view, is not that they include some idea of suffering, ${ }^{49}$ but that they are oppositional in nature. They involve, as Wallace explains, "being exercised about a past action that sets us against the agent of the action". It disposes us to stand up against her, and to confront and oppose her for what she has done. This in turn puts all of us into a form of social relation that we all have reasons and are strongly motivated to avoid. ${ }^{50}$ Given its oppositional nature, resentment and indignation must be merited, but it does not need to include the arguably more normatively problematic ideas of revenge and retribution.

To summarize, what I have been trying to do in this section is to argue for an answer to the following question that I proposed to ask in the section before: why do those who fail to properly engage with reasons in the way described by the Engagement View when they act merit and therefore are worthy of blame for what they have done, not simply in the thin sense of having an entry in their moral ledger, but also in the more robust sense of involving reactive attitudes like resentment and indignation? I have argued the answer to this question cannot plausibly be the mere fact that failing to do so when one acts reflects badly on one and shows one in a worse light. Rather, a more plausible answer is that one is morally required to properly engage (more precisely in the terminology of the Engagement View) the guiding reasons that bear on one's actions in one's practical reasoning, conformance to which is either owed to others or is something that others have good reasons to take seriously and/or care about. It is because of this, I argue, that one merits resentment and/or indignation for what one has done when one fails to do so when one acts. In the next section, I shall argue that for the same reason the outcomes of one's action can also merit resentment and therefore form part of the blame that one is worthy of for what one has done.

\footnotetext{
Footnote 46 (continued)

Emotions. The Moral Psychology of Anger (Rowan \& Littlefield 2018) 67-88. See also Srinivasan (n 44) $123-131$.

47 Justin D'Arms and Daniel Jacobson, 'The Significance of Recalcitrant Emotion (or, Anti-quasijudgementalism)' (2013) 52 Royal Institute of Philosophy Supplement 127, 143. Similarly, indignation is also anger that is 'cognitively sharpened' but with the belief that the target of one's indignation has either wronged others or has simply failed to do what morality requires of us.

48 See also Srinivasan (n 44) 129-130 and Wallace (n 45).

49 This does not imply that they can never appropriately include some more nuanced ideas of the wrongdoer suffering that are arguably much less normatively problematic than payback and retribution. See e.g. Srinivasan (n 44) 129 and Jules Holroyd, 'The Retributive Emotions: Passions and Pains of Punishment' (2010 39 Philosophical Papers 343, 355-360.

50 Wallace (n 45) 542.
} 


\section{Why the Outcomes of One's Actions can also Merit Blame}

We can see this by looking again at the example discussed before about how we all have a strong reason not to hurt others. What this requires of us, as I explained earlier, is not just that we properly engage with the reason not to hurt others in our practical reasoning when we act and not try to hurt them in our actions, we are also required to actually not hurt others through our actions, at least not unjustifiably. Indeed, it seems plausible to think that it is because we are morally required not to actually hurt others without justification that explains why we are required to properly engage with that reason in our practical reasoning and not try to hurt others in our actions. ${ }^{51}$ If failing to do what is morally required of one in one's practical reasoning can be grounds for meriting resentment for what one has done, then failing to do the same in one's actions can also be grounds for meriting resentment for what one has done.

Accepting that the outcome of one's actions can merit resentment in this way, however, does not commit one to the position that simply hurting someone without justification would alone be sufficient to merit resenting the person who did the hurting, even when she was not at fault at all or it was merely an accident. Many would find such a position implausible. While it is natural and understandable to resent someone when they have hurt us, many would think that it is objectionable to do so if they were not at fault at all or it was merely an accident. The issue here is not simply that there are stronger countervailing reasons against resenting them in such cases, but that they simply do not merit such a response, given that they were not at fault at all or that it was merely an accident. ${ }^{52}$

I think this is correct. I therefore do not think that simply hurting someone without justification alone is sufficient to merit resenting the person who did the hurting. What is also needed is there to be a connection between the outcome of one's actions and one's agency. A connection that is more than simply a causal one. Since I accept that the Engagement View is a plausible account of fault, and of when one is worthy of blame in relation to one's actions and their outcomes,${ }^{53} \mathrm{I}$ am therefore inclined to flesh out this connection in terms of the Engagement View. In other words, my view is that we should see the failure that is described by the Engagement View as a necessary condition for the outcomes of one's action to merit resentment. More specifically, the outcomes of our actions merit resentment only if we brought it about because of our failure to properly engage in our practical reasoning the guiding reason(s) that count against us bringing that outcome about. Accordingly, simply hurting someone without justification is alone not sufficient to merit resenting the person who did the hurting. It is so only if she brought it about as a

\footnotetext{
51 As argued by Edwards and Simester (n 1) 53-54.

52 At least not the kind of resentment that we are concerned with when we talk about moral blame. I am open to the possibility of other kinds of resentment being merited here.

${ }^{53}$ See discussion in $\mathrm{s} 3$.
} 
result of her failing to properly engage with the reason against hurting others without justification. ${ }^{54}$

This is not an ad hoc addition to what I have been arguing for. As I pointed out earlier when I was explaining the Engagement View, the reason why failing to properly engage with reasons in the way described by the Engagement View merits resentment is not simply that one has failed to do what one is morally required to do, but also that one has failed to do so in a way that can reasonably be expected of one. ${ }^{55}$ The same principle also applies here. We are morally required not to hurt others without justification, and whenever we end up doing so there is at least a cause for regret. ${ }^{56}$ However, we also cannot be reasonably expected to not hurt others without justification come what may. We realise that accidents can and do happen, and that despite how careful one is, one can still end up unjustifiably hurting others through one's actions. What can therefore be reasonably expected and demanded of us is not simply that we never hurt others unjustifiably, but that we do not do so or end up doing so by properly engaging with the reason against hurting others unjustifiably. It is only when we end up hurting someone as a result of such a failure on our part, does the fact that we ended up hurting someone merit resentment. Hence the necessary condition that I have argued for when the outcomes for one's actions can merit resentment.

Although the outcomes of our actions cannot merit resentment unless we brought it about through our failure to properly engage with reasons in the way described by the Engagement View, this does not simply reduce what I have been trying to argue for here into the Engagement View. What is meriting resentment here is the fact that one has actually hurt others unjustifiably and not that one has failed to properly engage with reasons in one's practical reasoning (or at least not that one has simply so failed). As I put it earlier, when it comes to the outcomes of one's action, failing to engage with reasons properly in one's practical reasoning should be understood as a necessary condition for the outcomes of one's action to merit resentment. It is an 'enabler' so to speak, that enables the outcomes of one's action to merit resentment and without which the same outcomes would not merit it. This does not mean, contrary to the Engagement View and what I have argued in the earlier sections, that failing to properly respond to reasons in such a way when one acts does not itself merit resentment. It still does, for something can itself be a ground for something else - say ' $\mathrm{X}$ ' - while at the same time enabling other things to ground additional Xs.

One way to take forward what I have argued for is to argue that those who manage to bring about the outcomes of their wrongful actions (e.g. assassin $\mathrm{A}$ in the example I began this paper with) are worthy of more blame for what they have done

\footnotetext{
${ }^{54}$ I am aware that this gives rise to many 'causal conundrums' - see e.g. Alexander and Ferzan (n 15) 180-188 - and that a complete defence of the Outcomes-sensitive View will need to properly address them. However, I shall set them aside given the purposes of this paper. See also text at $\mathrm{n} 58$.

55 See text at $\mathrm{n} 12$.

56 This is not to say that there is no cause for regret if we end up hurting others accidentally or even justifiably.
} 
than those who don't (e.g. assassin B in that example) because there are more things (so to speak) in what the former have done that merit resentment when compared to the latter. Thus, for example, not only did assassin A, like assassin B, fail to properly engage with the reason against killing her victim as she can reasonably be expected to in her practical reasoning; in actually killing her victim, she has also (unlike assas$\sin \mathrm{B}$ ) failed to actually conform to that reason as she can reasonably be expected to. Hence assassin A is worthy of more blame than assassin B because there are more things in what $\mathrm{A}$ has done that merit resentment when compared to $\mathrm{B}$.

The problem with this argument is that it can be criticised as implying that $\mathrm{A}$ is worthy of blame for more things than B, rather than A being worthy of more blame than B for what she has done. This is especially the case if we are to see each of A's moral failures as an independent wrong. According to this view, in actually killing her victim, A has committed an additional wrong when compared to B. However, this way of looking at things between A and B seems distorted. ${ }^{57}$ It is distorted because to the extent that $\mathrm{A}$ is worthy of more blame for what she has done when compared to $\mathrm{B}$, it is not the same as the case where one murderer is worthy of more blame than another simply because the former also stole when she committed the murder. This, however, is precisely the picture that is suggested by such a view of looking at things between $\mathrm{A}$ and $\mathrm{B}$.

A more plausible way forward (and arguably a more natural way of seeing things) is to argue instead that $\mathrm{A}$ is worthy of more blame than B for what she has done because in actually killing her victim, A has committed a more serious wrong in relation to what is morally required of her than $\mathrm{B}$, and therefore merits more blame and resentment for what she has done than B. As discussed before, we all have a strong reason not to hurt (or more relevant to the example at hand - kill) others. What this requires of us is not simply that we properly engage with this reason in our practical reasoning but that we do not hurt or kill, or end up hurting or killing, others by properly engaging with this reason in our practical reasoning. In actually killing her victim, A has therefore done worse in relation to this requirement than $\mathrm{B}$. Not only has she failed to properly engage with the reason in question as required when she decided to kill, she also actually killed her victim as a result of her decision to do so. B, on the other hand, also equally failed to properly engage with the reason in question in her practical reasoning. However, she did not manage to actually kill her victim (or anyone else) as a result of her decision to kill. She only managed to make an unsuccessful attempt at doing so. Given what A has done is worse than $\mathrm{B}$ in relation to what is morally required of them with respect to the reason not to hurt or kill others, A therefore merits more resentment and is worthy of more blame for what she has done than B for what B has done.

In this section, I have argued that the outcomes of one's action can also merit resentment and blame for the same reason that one's failure to properly engage with reasons as described by the Engagement View merits resentment and blame. This is because we are not simply morally required to properly engage with the reason

\footnotetext{
${ }^{57}$ See also Grant Lamond, 'Criminal Culpability and Moral Luck' (2021) 23 Jerusalem Review of Legal Studies 149, 162-163.
} 
against bringing about the outcomes in question. Rather, we are morally required to not bring them about by properly engaging with the reason against bringing them about in our practical deliberations when we act. I have also argued how, for those who manage to bring about those outcomes as a result of their failure to properly engage with the reason in question, they have done worse with respect to this moral requirement than those who similarly failed on the latter front but did not bring about the outcomes in question. It is for this reason that they merit more resentment and are worthy of more blame for what they have done. The outcomes of one's action can therefore, in this way, affect how much blame one is worthy of.

\section{Conclusion}

It is not the aim of this paper to argue against the Outcomes-insensitive View and in defence of the Outcomes-sensitive View. In order to fully defend the Outcomessensitive View, one will also need to properly address a number of established counter-examples, 'causal conundrums' and possible divergences between the judgements of blameworthiness that are implied by the view and our judgements of praiseworthiness. $^{58}$

The aim of this paper, however, has been much more limited and modest. I began by explaining at least two ways to argue for the Outcomes-insensitive View. The first one relies on the Control Principle while the second one relies on what it means to be blameworthy. What this paper has tried to argue for is simply that relying on what it means to be blameworthy, and in particular the Engagement View, does not necessarily show that we should accept the Outcomes-insensitive View as opposed to the Outcomes-sensitive View. It depends on what we take ourselves to be doing when we blame others; and if we understand blame more robustly as involving reactive attitudes like resentment and indignation, as I argue we should, then the Engagement View can also give us reasons for thinking that the outcomes of one's actions can affect how much blame one is worthy of. It is still open for one to defend the Outcomes-insensitive View by appealing to the Control Principle or some other account of blameworthiness. ${ }^{59}$ Nothing I have argued for in this paper precludes that. It is just that one cannot, if one accepts my arguments, make the case for the Outcomesinsensitive View simply by appealing to the Engagement View. One also needs to appeal to, for example, the Control Principle (or some other principle or arguments to the same effect), in order to establish that.

Putting aside the Control Principle and any other arguments for the Outcomesinsensitive View, let me end with two general implications about blameworthiness that can be drawn from my arguments in this paper. First, assuming that what one can properly be blamed for are just those aspects of what one has done that merit and give others reasons to blame the individual in question, then one implication

\footnotetext{
58 Alexander and Ferzan (n 15) 175-188. For an attempt at responding to some of these, see Lamond (n 57) $156-161$.

59 See text at $n 7$.
} 
of what I have argued for is that, ${ }^{60}$ contrary the view held by some, ${ }^{61}$ what one can properly be blamed for does matter to and indeed determines how blameworthy one is in the sense of how much blame one is worthy of. This, however, is not in tension with or against the argument that what makes one worthy of blame also determines how much blame one is worthy of. This is because what that argument amounts to is precisely that what makes one worthy of blame (i.e. failing to properly engage with reasons in the way described by the Engagement View) is at least part of what one can properly be blamed for.

Second, although being blameworthy shows one in a bad light, it does not mean, according to the view advanced in this paper, that one is shown or should be seen in a worse (or better) light just because one is merely being more (or less) blameworthy. This is because one might be worthy of more (or less) blame, according to my view, simply because of the outcome of one's action that is brought about by one's failure to properly engage with the reasons in question. Here it would be helpful to draw a distinction between being more (or less) worthy of blame and being worthy of more (or less) blame. One can be more (or less) blameworthy by (a) being more (or less) worthy of blame, (b) being worthy of more (or less) blame or (c) being both. ${ }^{62}$ The claim then is that insofar as two wrongdoers both failed to properly engage with reasons in the same way when they act, they both have shown themselves in an equally bad light and are equally worthy of blame for what they each have done. Nevertheless, one can still be more blameworthy than the other because one is worthy of more blame for what one has done than the other due to the outcomes of one's wrongful actions (or less because of the lack thereof).

Acknowledgements Many thanks to my colleagues at the Surrey Centre for Law and Philosophy and to the attendees of the Philosophy Spring Research Seminar at Nottingham for their comments on an earlier version of this paper. Special thanks are also owed to James Edwards, Sarah Henderson, Brian Ho, Gemma Yim and the two anonymous reviewers of this journal.

Open Access This article is licensed under a Creative Commons Attribution 4.0 International License, which permits use, sharing, adaptation, distribution and reproduction in any medium or format, as long as you give appropriate credit to the original author(s) and the source, provide a link to the Creative Commons licence, and indicate if changes were made. The images or other third party material in this article are included in the article's Creative Commons licence, unless indicated otherwise in a credit line to the material. If material is not included in the article's Creative Commons licence and your intended use is not permitted by statutory regulation or exceeds the permitted use, you will need to obtain permission directly from the copyright holder. To view a copy of this licence, visit http://creativecommons.org/licen ses/by/4.0/.

\footnotetext{
${ }^{60}$ This assumption is plausible. See e.g. analogous discussions about what it means for legal punishment to be something that is imposed for a legal offence by John Gardner in H L A Hart, Punishment and Responsibility $\left(2^{\text {nd }}\right.$ edn, OUP 2008) xxv.

${ }^{61}$ E.g. Edwards and Simester (n 1) 66 and Zimmerman (n 2) 560.

${ }^{62}$ D Justin Coates, 'Being More (or Less) Blameworthy' (2019) 56 American Philosophical Quarterly 233.
} 
Publisher's Note Springer Nature remains neutral with regard to jurisdictional claims in published maps and institutional affiliations. 